Cambridge Archaeological Journal

http://journals.cambridge.org/CAJ

Additional services for Cambridge Archaeological Journal:

ARCHAEOLOGICAL.

Email alerts: $\underline{\text { Click here }}$

Subscriptions: $\underline{\text { Click here }}$

Commercial reprints: Click here

Terms of use : Click here

\title{
Palaeolithic Populations and Waves of Advance
}

Joaquim Fort, Toni Pujol and Luigi Luca Cavalli-Sforza

Cambridge Archaeological Journal / Volume 14 / Issue 01 / April 2004, pp 53 - 61

DOI: 10.1017/S0959774304000046, Published online: 02 June 2004

Link to this article: http://journals.cambridge.org/abstract_S0959774304000046

How to cite this article:

Joaquim Fort, Toni Pujol and Luigi Luca Cavalli-Sforza (2004). Palaeolithic Populations and Waves of Advance. Cambridge Archaeological Journal, 14, pp 53-61 doi:10.1017/S0959774304000046

Request Permissions : $\underline{\text { Click here }}$ 


\title{
Palaeolithic Populations and Waves of Advance
}

\author{
Joaquim Fort, Toni Pujol \& Luigi Luca Cavalli-Sforza
}

\begin{abstract}
The wave-of-advance model has been previously applied to Neolithic human range expansions, yielding good agreement to the speeds inferred from archaeological data. Here, we apply it for the first time to Palaeolithic human expansions by using reproduction and mobility parameters appropriate to hunter-gatherers (instead of the corresponding values for preindustrial farmers). The order of magnitude of the predicted speed is in agreement with that implied by the AMS radiocarbon dating of the lateglacial human recolonization of northern Europe (14.2-12.5 kyr BP). We argue that this makes it implausible for climate change to have limited the speed of the recolonization front. It is pointed out that a similar value for the speed can be tentatively inferred from the archaeological data on the expansion of modern humans into the Levant and Europe (42-36 kyr вP).
\end{abstract}

From the density distribution of archaeological sites, it is well-established that during the Glacial Maximum (22-16.5 kyr вр) humans abandoned northern Europe in response to the cold, seeking refuge in milder areas (Dolhukhanov 1979; Hahn 1979; Kozlowski \& Kozlowski 1979; Bocquet-Appel \& Demars 2000a). Recently, Housley and co-workers (1997) performed a detailed archaeological dating for the northward recolonization of northern Europe by hunter-gatherers (Fig. 1). They applied criteria of sound stratigraphical context and unequivocal evidence for human modification of bones and neglected data affected by the use of chemical preservatives for dating, the measurements of questionable chemical fractions, etc. Their careful procedure made it possible for Housley et al. (1997) to show that a sequential, well-defined geographical pattern of recolonization is implied by the radiocarbon data. In this article we present a statistical analysis of their data, which allows us to derive the speed of the waves of advancing humans and its error as implied by regression analysis. We also compare this observational range to that predicted by the wave-of-advance model (Ammerman \& Cavalli-Sforza 1984; Fort \& Méndez 1999) and point out the applicability of the model and parameters discussed to other hunter- gatherer range expansions. The usefulness of such models is that, as we shall see, they make it possible to understand why human range expansions, which are important historical events, take place at the observed speeds and not faster or slower.

\section{The observed speed of recolonization}

As in the analysis of the Austronesian population expansion (Fort 2003), we select the oldest site in each of the geographic areas analyzed, in this case from the data by Housley et al. (1997). The location and names of the sites are shown in Figure 1. Each number in the map corresponds to the oldest postglacial recolonization site in a circular region with diameter of about $150 \mathrm{~km}$.

In Figure 2, we plot the radiocarbon dates (from Housley et al. 1997) for the sites shown in Figure 1 versus their corresponding great-circle distances to the oldest site discovered to date (Kesslerloch, Fig. 1:1). The slope of the regression line (solid line in Fig. 2) is $-1.23 \pm 0.22 \mathrm{yr} / \mathrm{km}$ and is significantly different from zero $(P<0.001)$. The corresponding speed is $0.8 \mathrm{~km} / \mathrm{yr}(0.5-1.1 \mathrm{~km} / \mathrm{yr}$ with 95 per cent confidence level). The dashed curves around this regression bound the 95 per cent confidence interval. 


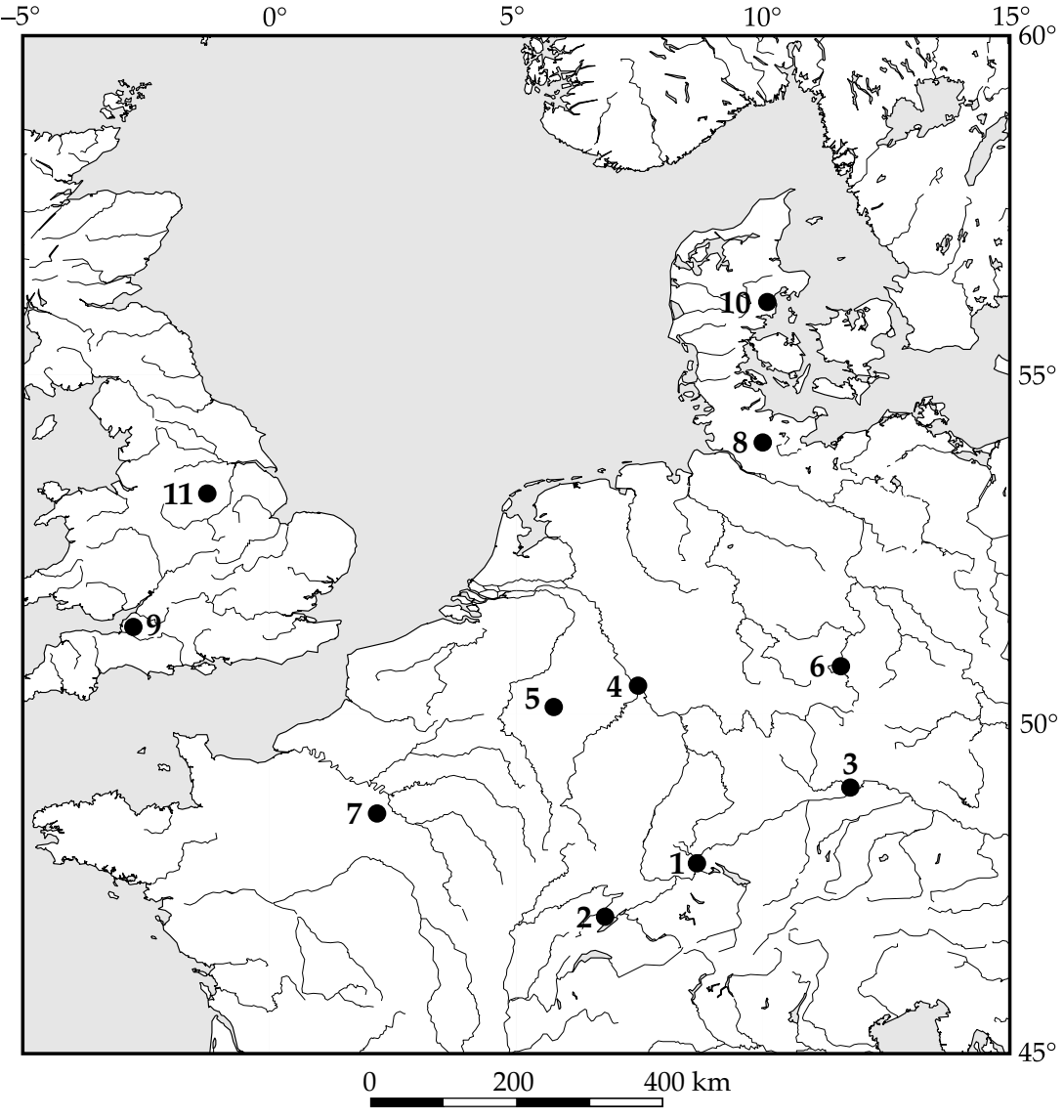

Figure 1. Map of northern Europe. Each number corresponds to the oldest postglacial recolonization site in a region with diameter of about $150 \mathrm{~km}$. The dates and distances of these sites, from Housley et al. (1997), are plotted in Figure 2: 1) Kesslerloch (Schaffhausen, Switzerland); 2) Munroz (Neuchatel, Switzerland); 3) Klausenhöhlen (southern Germany); 4) Andernach (Middle Rhine); 5) Trou des Blaireaux (Belgium); 6) Kniegrotte (eastern Germany); 7) Etiolles (Paris Basin); 8) Poggenwisch (northern Germany); 9) Gough's cave (Mendips, British Isles); 10) Solbjerg (Denmark); 11) Robin Hood's cave (Peak District, British Isles).

The reason to use the regression of times versus distances is that distance is in principle known exactly, whereas the radiocarbon dates are affected by error (see Sokal \& Rohlf 1981). It is true, however, that the actual migration routes may have been influenced by geographical barriers (such as mountains), the distribution of prey species and of gathering resources, etc. It is worth noting, however, that the magnitude of the correlation coefficient is high $(r=-0.81)$. This is why the regression of distances versus times (dotted line in Fig. 2) is rather similar to the former one, and it gives a similar statistical interval for the speed $(0.4-0.9 \mathrm{~km} / \mathrm{yr}$ with 95 per cent confidence level). We may note that the time-versus-distance confidence interval (dashed curves in Fig. 2) includes most of the observational points, which together with the high magnitude of the correlation coefficient supports the applicability of the wave-of-advance model. ${ }^{1}$ A low value of the correlation coefficient and the location of many points outside the confidence interval could be interpreted as the result of local perturbations (due, for example, to obstacles and geographic variations in the hunting and gathering resources) that would yield a nonuniform and / or non-isotropic value for the wavefront speed. This is not the case for the data from Housley et al. (1997), so that an overall estimation for the wavefront speed makes sense. Thus, in the next section, we will tackle the question of how the observed speed $(0.4-1.1 \mathrm{~km} / \mathrm{yr})$ may be explained.

For the case of the European Neolithic there are more data, and more reliable, than for the case considered here. This is why the observed speed for the Neolithic (0.8$1.2 \mathrm{~km} / \mathrm{yr}$ ) is less uncertain (compare Fig. 2 here to fig. 4.2 in Ammerman \& Cavalli-Sforza 1984). The statistical analysis above, however, shows that for the case of postglacial expansions, the data available at present are enough to make a first step in order to determine the observed speed. It is of course hoped that our analysis can be improved when more and better data become available in the future.

Note that in this section we have determined, by means of a rigorous statistical analysis, what Housley et al. (1997) call the pioneer-to-pioneer speed, which corresponds to the leading edge of the wavefront. The pioneer-to-residential speed of Housley et al. (1997) cannot be directly compared to the predictions of the wave-of-advance model because it is not the speed of a solution to the reactiondiffusion equation with constant shape (this requirement is necessary to derive Eq. (1) below, see Fort \& Méndez 1999 and references therein).

Before closing this section on the observed speed, we would like to mention that Blockley et al. (2000) have criticized the approach by Housley et al. 
(1997) on the following grounds.

i) They claim that a different way to analyze the data (namely, applying 2 sigma instead of 1 sigma errors) gives different values for the earliest dates. This does not, however, change the overall speed: comparing figures 1.a and 1.b in Blockley et al. (2000), it is seen that there is the same time interval between the earliest dates for the Upper Rhine and the British Isles, independently of the approach used.

ii) They propose to use a marine curve to calibrate the terrestrial samples considered by Housley et al. (1997). This has been questioned by Housley et al. in their response (Blockley et al. 2000, 119) and by other authors cited therein. Moreover, it has been argued that until there is consensus for a common calibration system in the Late Glacial, it is better to use uncalibrated dates to avoid confusion (Street \& Terberger 1999). This is why we have used uncalibrated dates, as in Housley et al. (1997). Even if the calibrations in Blockley et al. (2000) were applied, however, the value for the observed speed would be similar to ours. (Note, for example, that the whole time interval in our Fig. 2 is close to that implied by figs. 3 or 4 in Blockley et al. 2000.)

iii) Finally, in their figures 5 and 6 Blockley et al. (2000) use all dates from a given region, rather than the earliest ones in its sites, to estimate the earliest date of occupation in the region considered. As Blockley et al. (2000) themselves point out, such an approach is counterintuitive. In our opinion, it is also misleading, simply because the longer a site was occupied, the later its computed settlement date would be.

\section{Wave-of-advance model and parameter values}

The wave-of-advance model (Ammerman \& CavalliSforza 1984) is a mathematical model that leads to a prediction for the speed of advance of a population when it expands its range. As we shall see in more detail below, in order to make such a prediction, one needs some information on how individuals of the biological species concerned (humans in this case) migrate and reproduce.

The wave-of-advance model has been recently refined (Fort \& Méndez 1999) by incorporating the implications of two points which we now summarize.

i) Diffusion takes place in two dimensions: this is equivalent to say that individuals do not move only in the south-north or north-south directions (this would correspond to a one-dimensional

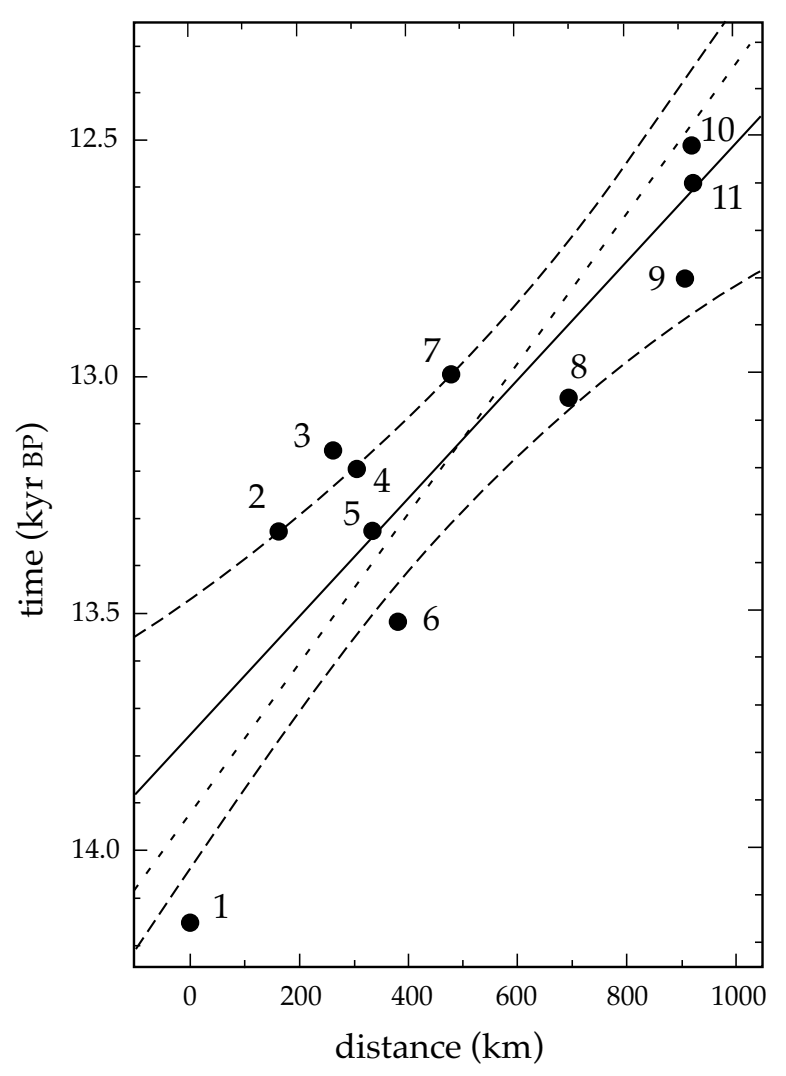

Figure 2. Determination of the wave-of-advance speed for the lateglacial recolonization of northern Europe. The number at each data point identifies the corresponding site in Figure 1. Distances are measured as great circle routes from the oldest site (Kesslerloch, number 1 in Fig. 1). Radiocarbon dates are from Housley et al. (1997). Times are plotted versus distances because of the error in the determination of dates. The continuous straight line is the linear regression fit, and the two dashed curves are 95 per cent confidence-level limits. Distances should not be regarded as without any error, as explained in the text; thus the linear regression of distances versus times is also shown (dotted line). The 95 per cent confidencelevel range implied for the speed is $0.4-1.1 \mathrm{~km} / \mathrm{yr}$.

space) but can also move in the east-west, northeast-southwest or any other direction, i.e. for any angle from $0^{\circ}$ to $360^{\circ}$.

ii) There is a delay owing to the mean generation time $\tau$ : this is equivalent to say that some time interval passes between the birth of an individual and the time when he or she leaves his/her parents. Such an interval is essentially the mean generation time $\tau$, i.e. the mean age difference between parents and their children.

After taking into account points (i) and (ii) above, the predicted speed is (Fort \& Méndez, 1999) 


$$
v=\frac{\sqrt{a m}}{1+\frac{a \tau}{2}},
$$

where $a$ is the initial growth rate of the population, ${ }^{2}$ $m$ is the mobility ${ }^{3}$ and $\tau$ is the mean generation time (mean age difference between parents and their progeny). Making the diffusion process discontinuous in time introduces a delay, witnessed by the denominator in Eq. (1), which does not appear in the continuous diffusion process modelled by R.A. Fisher and used by Ammerman \& Cavalli-Sforza (1984). From Eq. (1), we see that higher values of either $a$ or $m$ will lead to a faster population range expansion, as should be expected intuitively, while the existence of a delay caused by $\tau$ will cause a decrease of the rate of advance approximately proportional to $\tau$.

Let us briefly discuss the role of the generation time $\tau$. When a biological species expands its range, some of the individuals migrate to previously empty areas. The generation time is taken as an estimation of the mean time between two subsequent migrations, namely those of the parents and of some of their progeny. This does not imply, however, that individuals migrate only once in their lifetime. Consider for example the case of slash-and-burn agriculturalists. In this case, land is used in a cyclic way so that migrations do happen every few years (Stauder 1971). Once the abandoned areas have recovered their fertility, they are slashed and cultivated again (let us refer to this phenomenon as 'field rotation'). Thus, when a time span of, say, two decades is considered, a productive group occupies a land area that is in fact higher than that they use during, say, a given year. This may also be stated by saying that the true population density (number of people per unit cultivated area) is lower than the value that would be inferred if only the fields being cultivated per year were considered. This is why, in the waveof-advance model and Eq. (1), the parameters $\tau$ and $m$ do not correspond to all 'jumps' but only to one jump per generation (e.g. a son leaving their parents). The effect of other 'jumps' (e.g. field rotations) is included in the population density that appears in the reaction-diffusion equations leading to Eq. (1) (Ammerman \& Cavalli-Sforza 1984; Fort \& Méndez 1999). But the speed, as given by Eq. (1), is independent of the population density or of its carrying capacity (which is defined as the population density when the population stops growing). Thus, such other 'jumps' do not affect the speed. In contrast, the mean time interval between subsequent migrations $\tau$ does appear in Eq. (1) because when the population grows, it is reasonable and consistent with anthropological evidence to consider that some of the sons and daughters will migrate, establish elsewhere and have sons. This is why the value of $\tau$ is expected to be similar to the mean generation time.

Eq. (1) implies that a higher value of the mean generation time $\tau$ will lead to a slower wave of advance, as should be expected intuitively. In the case of hunter-gatherers, individuals again change their location many times during their lifetime. Similarly to slash-and-burn agriculturalists, this happens in a cyclic way for hunter-gatherers also (Flood 1976; Turnbull 1986). On the other hand, it is reasonable to assume that if the population expands its range, part of the progeny will, after they have grown up, disseminate into previously unpopulated areas. This is why the mean generation time $\tau$ and the mean squared displacement $m$, also per generation, appear in Eq. (1).

It is very important to stress that, as noted explicitly by Bar-Yosef (2002), the wave-of-advance theory gives an overall description that is compatible with more detailed models which take into account the preference of certain environments by the migrating populations (Van Andel \& Runnels 1995). Both approaches are alternative descriptions of the same process (Bar-Yosef 2002). The same happens in physics, where transport phenomena can be modelled either by means of macroscopic equations or by the kinetic theory, which corresponds to a more detailed description. Again, the macroscopic equations follow when one averages the microscopic, kinetic ones, so both approaches are consistent (Chapman \& Cowling 1990; Jou et al. 2001).

Let us return to the problem of human range expansions, which is in fact an example of transport process. The macroscopic, wave-of-advance model makes it possible to derive a quantitative prediction for the overall speed from Eq. (1), whereas the level of detail attained by non-homogeneous models (Van Andel \& Runnels 1995) makes them appropriate for the description of the observed clustered distribution of archaeological sites (Ammerman 2002). Both approaches are compatible and one can choose that which is more adequate to deal with the problem at hand. Here we are concerned with the speed of the advance wave. In the previous section we have seen that the available data are consistent with an overall constant and uniform speed (Fig. 2). Therefore we shall apply the wave-of-advance model, which gives a specific, testable prediction for the speed (Eq. (1)). In this context, it is worth mentioning that a time- 
delayed wave-of-advance model has been very recently applied successfully to explain the range expansion of a completely different biological population, namely T7 viruses in a medium composed of agar and E. Coli cells. In this case, the speeds predicted under various conditions are in agreement with those observed in the laboratory experiments (Fort \& Méndez 2002). That application, together with the satisfactory predictions of the wave-of-advance model for Neolithic populations (Fort \& Méndez 1999; Fort 2003), makes it a reasonable candidate to describe the range expansions of huntergatherers.

In order to avoid any possible confusion, it is worth stressing that all wave-of-advance models so far applied assume that new generations of individuals wander without any preferred direction. In the case of Neolithic populations (Ammerman \& Cavalli-Sforza 1984; Fort \& Méndez 1999; Fort 2003), people wander in search of new lands to farm. In the case of Palaeolithic populations (present article), they wander in search of food resources to hunt and/or gather.

In order to apply the time-delayed wave-ofadvance model, we need numerical values for the parameters $m, a$ and $\tau$ so that we can compute the speed predicted by Eq. (1). Previous studies on human expansions dealt with waves of advance of Neolithic communities, thus the theoretical predictions made use of parameters derived from anthropological observations of preindustrial farmers. This approach was applied to the Neolithic transition in Europe (Ammerman \& Cavalli-Sforza 1984; Fort \& Méndez 1999) and Oceania (Fort 2003). Here we are dealing with hunter-gatherers instead of farmers. Therefore the necessary parameter values ( $m, a$ and $\tau)$ have to be derived from the ethnography of huntergatherers. Nevertheless, it will be interesting to discuss briefly their differences from the corresponding data for preindustrial farmers.

Values of the mobility per generation $m$ used in models of the Neolithic transition in Europe were estimated from observed distributions of distances between birthplace and place of residence of the Gilishi and Shiri communities of the Majangir, who are slash-and-burn agriculturalists in Ethiopia (Stauder 1971). The range of values for $m$ implied by those data is $1100-2200 \mathrm{~km}^{2}$ per generation (Ammerman \& Cavalli-Sforza 1984, 155). For hunter-gatherers, $m$ can again be estimated from the distributions of distances between birthplace and place of residence. For Aka and Bofi-Aka African pygmies, such distributions were recorded (Hewlett et al. 1986) and they yield the range $1400-3900 \mathrm{~km}^{2} /$ generation for $m$. We note that there is a wide uncertainty range in both cases, but the mean mobility of hunter-gatherers is higher. This may also be observed from the distributions of distances between the birthplaces of spouses (Ammerman \& Cavalli-Sforza 1984, 79; Hewlett et al. 1986), although in general this does not correspond directly to the displacement per individual and generation (Hewlett et al. 1986).

The initial growth rate of farmers is known rather precisely. Birdsell (1957) collected data for human populations who settled in empty space at different times and places (Bass Strait Islands and the Pitcairn island). When the population size is plotted against the generations of elapsed time, there is excellent agreement between both sets of data, yielding the range for $a 0.73-0.86$ gen $^{-1}$. If a mean generation time of $25 \mathrm{yr}$ is used (Ammerman \& Cavalli-Sforza 1984, 156) this yields the range 0.029$0.035 \mathrm{yr}^{-1}$ for $a$. It is very interesting that for the U.S. colonization in the nineteenth century, Lotka (1956) obtained essentially this same value for $a$. In fact, for the U.S. colonization there are historical census data for many different regions (http: / / fisher.lib.virginia. edu/census/) and they give very similar results (D. Campos pers. comm.). Thus the range of $a$ is known rather precisely for agricultural populations.

It may be useful to remember that in the waveof-advance theory, the growth rate $a$ refers to the initial growth at the beginning of the logistic curve, ${ }^{1}$ which is the fastest, and applies only at the front of the wave of advance, because there the population density is very small.

The few modern hunter-gatherers still in existence are rather restricted in their growth by extreme limitations in the environment they occupy, and have a rate of growth very close to zero or often negative and are, moreover, mostly in transition to other economies. As far as we know, similar data series to those quoted above are not available for huntergatherers, but the differences in fertility between preindustrial farmers and hunter-gatherers are wellknown. They may be used to estimate the value of $a$ for hunter-gatherers by means of the formula ${ }^{4}$

$$
a=\ln \frac{f(1-M)}{2},
$$

where $a$ is the initial growth rate per generation, ${ }^{3} f$ is the fertility rate (mean number of children per woman at the end of her reproductive life) and $M<1$ is the subadult mortality rate, which is essentially the same for preindustrial populations, independently of whether they are farmers or hunter-gatherers (Sellen 


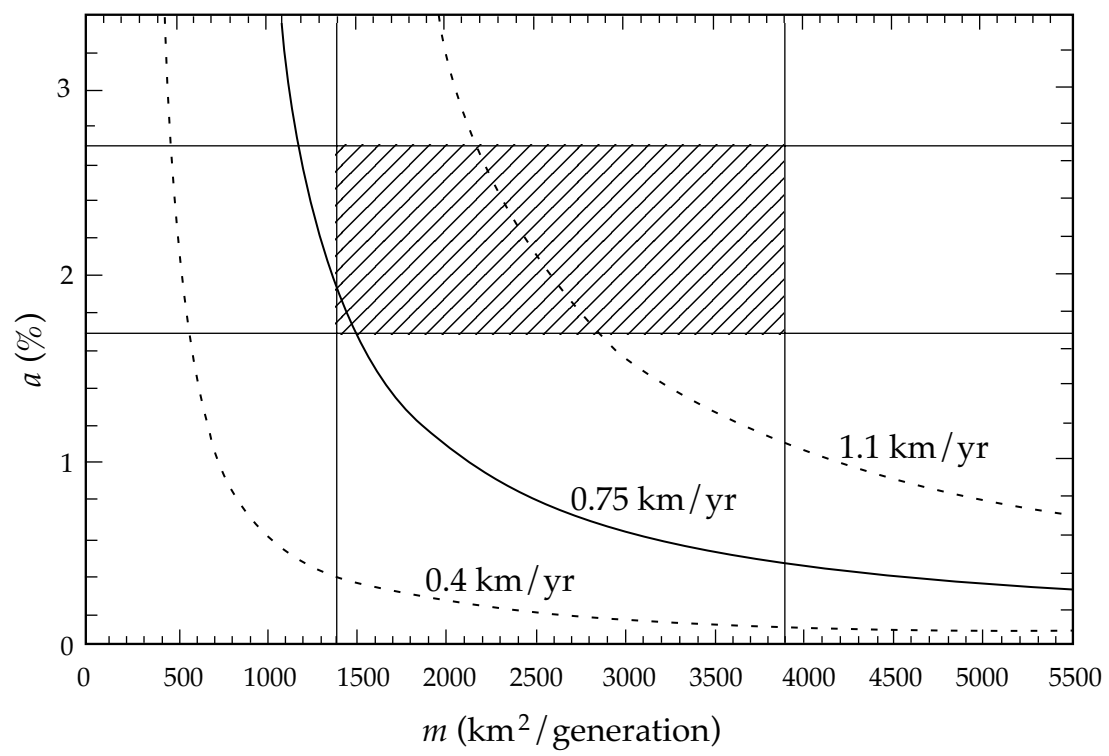

Figure 3. Comparison between the predictions of the wave-of-advance model and observations. The hatched rectangle corresponds to the allowed ranges of values for the parameters a and $m$ (Table 1). The curves give the values of a and $\mathrm{m}$ that predict a value for the speed of $0.4,0.75$ and $1.1 \mathrm{~km} / \mathrm{yr}$. It is seen that the observed speed range $(0.4-1.1 \mathrm{~km} / \mathrm{yr}$, from Fig. 2) is consistent with the predictions of the model.

2000, 52 \& table 2). Thus, if the fertilities of huntergatherers and farmers $\left(f_{H G}\right.$ and $f_{F}$, respectively) are known, their initial growth rates $a_{H G}$ and $a_{F}$ (measured in gen $^{-1}$ ) can be related through

$$
a_{H G}=a_{F}+\frac{\ln f_{H G}}{\ln f_{F}} .
$$

The fertilities of many preindustrial populations have been measured, yielding consistent results of $f_{H G}=$ 5.3 and $f_{F}=6.5$ (Sellen \& Mace 1997). Then Eq. (3) and the range above for $a_{F}$ yield the range for $a_{H G}$ $0.52-0.66$ gen $^{-1}$. In order to convert this into year units, it must be taken into account that huntergatherers have a mean interval between successive births that is about two years higher than the corresponding one for preindustrial farmers (Ammerman \& Cavalli-Sforza 1984). A generation time of 27 years is also suggested by Weiss (1973). Thus we use a mean generation time of 27 years for hunter-gatherers. The range above for $a_{\mathrm{HG}}$ is $0.019-0.025 \mathrm{yr}-{ }^{1}$, or $1.9-2.5 \%$. We will allow for the wider range $0.017-$ $0.027 \mathrm{yr}^{-1}$, or $1.7-2.7 \%$, so as to allow for possible uncertainties in the determination of the fertility rates and generation times used in the estimation of $a_{H G}$ above.

\section{Discussion}

Table 1 compares the relevant parameters for farmers and huntergatherers, which have been obtained in the previous section. As noted above, mobility is higher for hunter-gatherers. From Eq. (1) it is clear that this tends to yield higher speeds. The growth rate and mean generation time, however, are lower for hunter-gatherers, which has the opposite effect. Indeed, from the mean values in Table 1 and Eq. (1) one obtains $v=$ $1.0 \mathrm{~km} / \mathrm{yr}$ for farmers and $1.1 \mathrm{~km} /$ $\mathrm{yr}$ for hunter-gatherers, which are similar speeds as far as the order of magnitude is concerned.

Changing the value of the mean generation time leads to much the same result for the speed (Fort \& Méndez 1999). In Figure 3 we present the predictions of Eq. (1) for the ranges of $a$ and $m$ for hunter-gatherers estimated above (hatched rectangle in Fig. 3). It is seen that Eq. (1) predicts a speed $v$ between 0.7 and $1.4 \mathrm{~km} / \mathrm{yr}$. Since the speed determined from the archaeological data is $0.4-1.1 \mathrm{~km} /$ yr (Fig. 2), we see that the wave-of-advance model is consistent with the observed speed. It must be noted, however, that agreement holds only for the lower range of the mean-squared displacement per generation $\left(m<3000 \mathrm{~km}^{2} /\right.$ gen $)$. This shows that (i) the wave-of-advance model is consistent with available evidence; (ii) more data on the mobility of hunter-gatherers would be useful to narrow further the predictions of the model. Also, we stress again that, if the number of archaeological sites is increased by future discoveries, it will be possible to determine the observed speed more precisely (compare Fig. 2 here to fig. 4.2 in Ammerman \& Cavalli-Sforza 1984).

It may be argued that if the return to mild conditions after the glaciation had been sufficiently slow, it could in principle have slowed down the hunter-gatherers' recolonization. This seems unlikely, however, if we take into account that, according to the evidence available at present:

i) the ice sheets were well to the north of the area examined by 13,000 yr вр (Housley et al. 1997, fig. $1)$; 
Table 1. Comparison between typical values for the diffusion (m), delay $(\tau)$ and growth (a) parameters for preindustrial farmers and hunter-gatherers. The most difficult parameter to estimate is the mobility $\mathrm{m}$. The value of the mean generation time $\tau$ has little effect on the speed predicted by Eq. (1) (Fort \& Méndez 1999). Note that hunter-gatherers are more mobile but have a smaller initial growth rate because their fertility is lower. The way estimations have been performed is explained in the text.

\begin{tabular}{lll} 
& preindustrial farmers & hunter-gatherers \\
$m$ (km $^{2} /$ generation $)$ & $1100-2200$ & $1400-3900$ \\
$\tau$ (years) & $\mathbf{2 5}$ & $\mathbf{2 7}$ \\
$a$ (years- $\left.{ }^{1}\right)$ & $0.029-0.035$ & $0.017-0.027$ \\
\hline
\end{tabular}

ii) archaeological remains dated 40,000 yr вр have been recently found in the Russian Arctic (Pavlov et al. 2001); and

iii) temperature and pollen diagrams indicate that the climate after $15,000 \mathrm{yr}$ BP was significantly milder than 40,000 yr вр (Gowlett 2001, fig. 1).

Although the timing of ice cover melt as a function of location is not known precisely (Crowley \& North 1991; Gowlett 2001), these arguments make it implausible that it could have lowered the speed of the hunter-gatherers' population front. The argument may be reversed by saying that the speed of the observed recolonization (Fig. 2) can be regarded as evidence for a return to mild conditions after the glaciation at a speed of at least $0.4 \mathrm{~km} / \mathrm{yr}$. If the environmental conditions that previously forced humans to abandon northern Europe had improved at a slower rate, it would not have been possible for them to recolonize the north at this speed. The order-of-magnitude agreement with the model predictions (Fig. 3), which does not incorporate climate change but assumes an uniform habitat, is satisfactory and consistent with this view.

It is well-known from palaeoclimatology that the European climate deteriorated again once the hunter-gatherer recolonization here discussed was completed. This new cooling happened during the so-called Younger Dryas ( 10,000-11,000 yr вP). The North Atlantic polar front came back towards the south, sweeping again all of northern Europe (Crowley \& North 1991, fig. 3.16). Did this event cause a new depopulation of northern Europe and, if so, what was the speed of the new recolonization front? At present we do not know the answers, but archaeological data could be useful to solve this problem in the future. Moreover, according to the environmental data available, warming periods $(\sim 13,000 \mathrm{yr}$ вР for the lateglacial, $\sim 10,000 \mathrm{yr}$ вр for the Yonger Dryas) were very rapid, whereas the cooling ( 13,000-10,000 yr вP) was much slower (see e.g. Crowley \& North 1991, fig. 3.13). This may indi- cate that the speed of depopulation fronts was in fact limited by the climatic rate of change, while recolonization ones were not, as discussed above for the lateglacial. It will be possible to test such a general framework against empirical evidence only when numerous and sufficiently accurate archaeological data for the processes mentioned become available.

Finally, it is worth mentioning that there are some data for a different hunter-gatherer range expansion, namely that into the Levant and Europe by modern humans (42-36 kyr вг). It is interesting that in this case, the few data available (see e.g. Bar-Yosef \& Pilbeam 2000; Stringer et al. 2000; Gibbons 2001, 1725 ) imply that the incoming human wavefront travelled a distance of some $3000 \mathrm{~km}$ during $6000 \mathrm{yr}$, which would correspond to a speed of about 0.5 $\mathrm{km} / \mathrm{yr}$. This should not be regarded at all as a precise value for the speed, however, because the data are scarce and rather uncertain: the oldest sites have a dating error of $\sim 2000 \mathrm{yr}$ (Bar-Yosef et al. 1996), which could lead to a change in the speed of a factor of two. In comparison, for the late glacial wave of advance we have discussed, the typical dating error is $\sim 150 \mathrm{yr}$ (Housley et al. 1997). This, and the scarcity of dated sites, is why a detailed statistical analysis does not seem appropriate at present in the case of the original wave of advance of modern humans. It is very interesting, however, that:

i) additional data by Bocquet-Appel \& Demars (2000b) (especially Figs. 8.d \& 8.e) indicate a speed of about $0.8 \mathrm{~km} / \mathrm{yr}$ for the expansion of modern humans across Europe, which is very similar to the estimation of $0.5 \mathrm{~km} / \mathrm{yr}$ above;

ii) this order of magnitude for the speed is the same as that observed for the lateglacial recolonization (0.4-1.1 km/yr, from Fig. 2) and with that predicted by the wave-of-advance model (Fig. 3).

Thus, we have presented a methodology that can be useful also in the future, when the number and precision of the archaeological data allow for more precise determinations of the speeds for other huntergatherer waves of advance.

\section{Acknowledgements}

We thank D. Campos for information on webpages with historical census data on the U.S. colonization and their implied values for $a$. Suggestions by M.T. de Pouplana on a previous version are also acknowledged. Computing equipment was funded in part by the CICYT of the Ministry of Science and Technology under grants BFM2000-0351 (JF) and REN2000-1621 CLI (JF and TP). 


\section{Notes}

1. The magnitude $|r|$ of the correlation coefficient $r$ always satisfies that $0 \leq|r| \leq 1$. If this magnitude has a high value, as in our case, it means that the data points are close to the fitted straight line (Fig. 2), i.e. that the data support a linear relationship between space (moved by the wave of advance) and time. A linear relationship between space and time is equivalent to a constant speed, which is a prediction of the wave-of-advance model.

2. Biological populations, including human ones, are observed to grow exponentially in number if they consist of sufficiently few individuals initially. The exponent is proportional to the time elapsed, and the proportionality constant is called the initial growth rate (we denote it with the symbol $a$ ). Because food and space available are not infinite, however, an exponential increase cannot be maintained indefinitely, and at some point the population number begins to increase more slowly, until it eventually stops growing. The population number is thereafter a constant. Thus the typical population number-versus time curve has an ' $S$ ' shape. The mathematically-simplest such curve is called the logistic curve. For more information, see e.g. Lotka (1956).

3. The mobility $m$ is the mean-squared displacement per generation. For example, if an individual has moved $1.5 \mathrm{~km}$ away from his or her birthplace and a second individual has moved $2 \mathrm{~km}$ away from his or her birthplace, then their mean (or average) square displacement is $m=\left(1.5^{2}+2^{2}\right) / 2$. In practice one averages over many, rather than only two, individuals in order to estimate $m$. The reason why distances are squared is that otherwise the derivation of Eq. (1) (Fort \& Méndez 1999) would not be valid.

4. This is a well-known formula (Hassan 1981, 139). A simple derivation is possible: as explained in note 1 , an initially low population density $n$ will grow exponentially, as $n=n_{t=0} e^{a t}$. From this, we can evaluate $n$ at $t=1$ generation, which yields

$$
a=\ln \frac{n_{t=1 \text { generation }}}{n_{t=0}}
$$

The fraction inside the logarithm is obviously the fecundity (number of children per woman) divided by two (because $n$ includes men in addition to women) and corrected by the mortality. In this way we obtain Eq. (2).

5. Eq. (3) follows from writing Eq. (2) for farmers:

$$
a_{F}=\ln \frac{f_{F}(1-M)}{2}
$$

and for hunter-gatherers:

$$
a_{H G}=\ln \frac{f_{H G}(1-M)}{2},
$$

and subtracting both equations.
Joaquim Fort

Departament de Física, Universitat de Girona Campus de Montilivi, 17071 Girona

Catalonia

Spain

Email: joaquim.fort@udg.es

Toni Pujol

Departament de Física, Universitat de Girona Campus de Montilivi, 17071 Girona

Catalonia

Spain

Email: toni.pujol@udg.es

Luigi Cavalli-Sforza

Department of Genetics

Stanford University School of Medicine

300 Pasteur Drive

Stanford, CA 94305-5120

USA

\section{References}

Ammerman, A., 2002. Agriculture: spread of agriculture, in Oxford Encyclopaedia of Evolution, ed. M. Pagel. Oxford: Oxford University Press.

Ammerman, A. \& L.L. Cavalli-Sforza, 1984. The Neolithic Transition and the Genetics of Populations in Europe. Princeton (NJ): Princeton University Press.

Bar-Yosef, O., 2002. Natufian and the Early Neolithic: social and economic trends in southwestern Asia, in Examining the Farming/Language Dispersal Hypothesis, eds. P. Bellwood \& C. Renfrew. (McDonald Institute Monographs.) Cambridge: McDonald Institute for Archaeological Research, 113-26.

Bar-Yosef, O. \& D. Pilbeam, 2000. The Geography of Neandertals and Modern Humans in Europe and the Greater Mediterranean. Cambridge (MA): Peabody Museum of Archaeology and Ethnology and Harvard University.

Bar-Yosef, O., M. Arnold, N. Mercier, A. Belfer-Cohen, P. Goldberg, R. Housley, H. Laville, L. Meignen, J.C. Vogel \& B. Vandermeersch, 1996. The dating of the upper Palaeolithic layers in Kebara Cave, Mt Carmel. Journal of Archaeological Science, 23, 297-306.

Birdsell, J.P., 1957. Some population problems involving Pleistocene Man. Cold Spring Harbor Symposium in Quantitative Biology 22, 47-69.

Blockley, S.P.E., R.E. Donahue \& A.M. Pollard, 2000. Radiocarbon calibration and late glacial occupation in northwest Europe. Antiquity 74, 112-21.

Bocquet-Appel, J.-P. \& P.-Y. Demars, 2000a. Population kinetics in the Upper Palaeolithic in Western Europe. Journal of Archaeological Science 27, 551-70.

Bocquet-Appel, J.-P. \& P.-Y. Demars, 2000b. Neanderthal contraction and modern human colonization of Eu- 
rope. Antiquity 74, 544-52. [For a criticism and the authors' countercriticism, see Pettitt, P.B. \& A.W.G. Pike, 2001. Blind in a cloud of data: problems with the chronology of Neanderthal extinction and anatomically modern human expansion. Antiquity 75, 415-20.]

Cavalli-Sforza, L.L. (ed.), 1986. African Pygmies. Orlando (FL): Academic Press.

Chapman, S. \& T.G. Cowling, 1990. The Mathematical Theory of Non-uniform Gases: an Account of the Kinetic Theory of Viscosity, Thermal Conduction and Diffusion in Gases. 3rd edition. Cambridge: Cambridge University Press.

Crowley, T.J. \& G.R. North, 1991. Paleoclimatology. Oxford: Oxford University Press.

Dolhukhanov, M., 1979. Evolution des systèmes écosociaus en Europe durant le pléistocène récent et le début de l'holocène, in La Fin des Temps Claciaires en Euopre: chronostratigraphie et écologie des cultures $d u$ Paléolithique final, ed. D. de Sonneville-Bordes. Paris: Colloques internationaux CNRS 271, 869-76.

Flood, J., 1976. Man and ecology in the highlands of southeastern Australia, in Tribes and Boundaries in Australia, ed. N. Peterson. Canberra: Australian Institute of Aboriginal Studies, 30-49.

Fort, J., 2003. Wave-of-advance model for the Austronesian population expansion. Antiquity 77, 520-30.

Fort, J. \& V. Méndez, 1999. Time-delayed theory of the Neolithic transition in Europe. Physical Review Letters $82,867-71$.

Fort, J. \& V. Méndez, 2002. Time-delayed spread of viruses in a growing plaque. Physical Review Letters $89,178101,1-4$.

Gibbons, A., 2001. The riddle of coexistence. Science 291, $1725-9$.

Gowlett, J.A.J., 2001. Out in the cold. Nature 413, 33-4.

Hahn, J., 1979. Essai sur l'écologie du Magdalénien dans la Jura souabe, in La Fin des Temps Claciaires en Euopre: chronostratigraphie et écologie des cultures du Paléolithique final, ed. D. de Sonneville-Bordes. Paris: Colloques internationaux CNRS 271, 869-76.

Hassan, F., 1981. Demographic Archaeology. New York (NY): Academic Press.

Hewlett, B.S., J.M.H. Van de Koppel \& L.L. Cavalli-Sforza, 1986. Exploring and mating range of Aka Pygmies of the Central African Republic, in Cavalli-Sforza (ed.), 65-79.

Housley, R.A., C.S. Gamble, M. Street \& P. Pettitt, 1997. Radiocarbon evidence for the lateglacial human recolonisation of northern Europe. Proceedings of the Prehistoric Society 63, 25-54.

Jou, D., J. Casas \& G. Lebon, 2001. Extended Irreversible Thermodynamics. 3rd edition. Berlin: Springer.

Kozlowski, J.K. \& S.K. Kozlowski, 1979. Upper Palaeolithic and Mesolithic in Europe: taxonomy and palaeohistory. (Prace Komisji, Archeologicznej 18.) Warsaw: Polska Akadamia Nauk.

Lotka, A.J., 1956. Elements of Mathematical Biology. New
York (NY): Dover.

Pavlov, P., J.I. Svendsen \& S. Indrelid, 2001. Human presence in the European Arctic nearly 40,000 years ago. Nature 413, 64-7.

Sellen, D.W., 2000. Relationships between fertility, mortality and subsistence: results of recent phylogenetic analyses, in Humanity from African Naissance to Coming Millennia, eds. P.V. Tobias, M.A. Rath, J. MoggiCecchi \& G.A. Doyle. Firenze: Firenze University Press, 51-64.

Sellen, D.W. \& R. Mace, 1997. Fertility and mode of subsistence: a phylogenetic analysis. Current Anthropology 38, 878-89.

Sokal, R.R. \& F.J. Rohlf, 1981. Biometry. 2nd edition. San Francisco (CA): Freeman.

Stauder, J., 1971. The Majangir: Ecology and Society of a Southwest Ethiopian People. Cambridge: Cambridge University Press.

Street, M. \& T. Terberger, 1999. The last Pleniglacial and the human settlement of Central Europe: new information from the Rhinesland site Wiesbaden-Igstadt. Antiquity 73, 259-72.

Stringer, C.C., R.N.E. Barton \& J.C. Finlayson (eds.), 2000. Neanderthals on the Edge: 10th Anniversary Conference of the Forbers' Quarry Discovery, Gibraltar. Oxford: Oxbow Books.

Turnbull, C.M., 1986. Survival factors among Mbuti and other hunters of the Equatorian African rain forest, in Cavalli-Sforza (ed.), 103-23.

Van Andel, T.H. \& C.N. Runnels, 1995. The earliest farmers in Europe. Antiquity 69, 481-500.

Weiss, K.M., 1973. Demographic models for Anthropology. American Antiquity 38, 1-186.

\section{Author biographies}

Joaquim Fort is a physicist. His research first dealt with cosmology and thermodynamics. His present research interests focus on the application of physical models to human migrations, animal range expansions, virus infections, economic inequality, linguistics, etc. He is assistant professor in Physics at the University of Girona (Catalonia, Spain).

Toni Pujol is a physical meteorologist. He works on climate dynamics and its effect on biological species, as well as their feedback on the climate. Some such simplified models consider how the reflectivity of the biota affects the net absorption of radiation by the Earth, and thus its climate.

Luigi Luca Cavalli-Sforza is a world expert on human genetic diversity. By collecting genes and analyzing data from archaeology, linguistics, etc., he was able to create the first quantitative model of diffusion of agriculture in the Neolithic Age. He is Professor Emeritus (active) at the School of Medicine, Stanford University (USA). 


\section{Now available}

\section{McDonald Institute for Archaeological Research}

University of Cambridge

Downing Street, Cambridge

CB2 3ER, UK.

Tel: $+441223333538 / 339336$
Fax: +441223333536

Title: Examining the farming/language dispersal hypothesis

Editors: Peter Bellwood and Colin Renfrew

Series: McDonald Institute Monographs

Classifications: Archaeology; Historical Linguistics;

Binding: Cloth

Genetics; Farming origins

Size: $286 \times 220 \mathrm{~mm}$

Pages: xiv+505 pp.; 80 illustrations, 25 tables

ISBN: 1-902937-20-1 hardback

ISSN: $1363-1349$

Price: $£ 50$; US\$85

Publication date: July 17, 2003

Distributor: Oxbow Books, Park End Place, Oxford, OX1 1HN, UK. Tel: (01865) 241249; www.oxbowbooks.com - or - David Brown Book Co., P.O. Box 511, Oakville, CT 06779, USA. Tel: 860-945-9329; Fax 860-945-9468

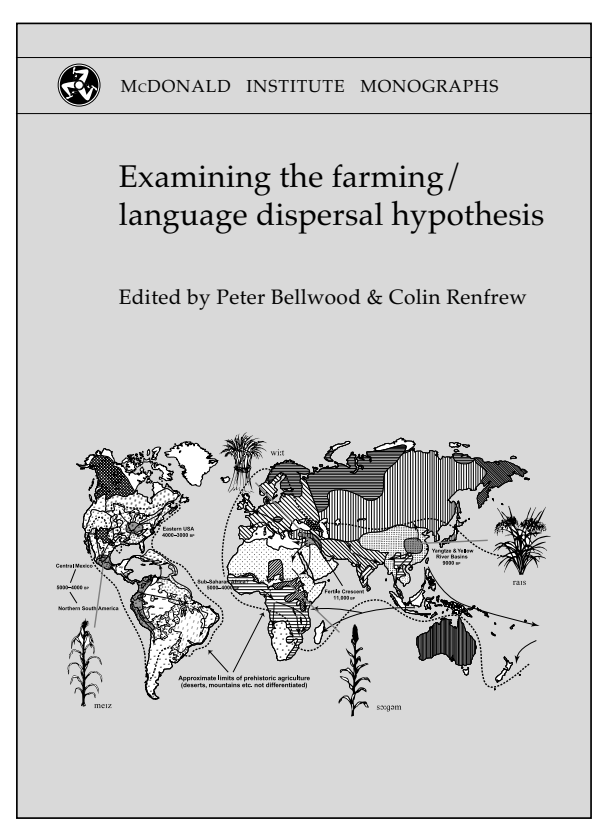

inguistic diversity is one of the most puzzling and challenging features of humankind. Why are there some six thousand different languages spoken in the world today? Why are some, like Chinese or English, spoken by millions over vast territories, while others are restricted to just a few thousand speakers in a limited area? The farming/language dispersal hypothesis makes the radical and controversial proposal that the present-day distributions of many of the world's languages and language families can be traced back to the early developments and dispersals of farming from the several nuclear areas where animal and plant domestication emerged. For instance, the Indo-European and Austronesian language families may owe their current vast distributions to the spread of food plants and of farmers (speaking the relevant proto-languages) following the Neolithic revolutions which took place in the Near East and in Eastern Asia respectively, thousands of years ago.

In this challenging book, international experts in historical linguistics, prehistoric archaeology, molecular genetics and human ecology bring their specialisms to bear upon this intractable problem, using a range of interdisciplinary approaches. There are signs that a New Synthesis between these fields may now be emerging. This path-breaking volume opens new perspectives and indicates some of the directions which future research is likely to follow. 